\section{Good-bye slippage - a new fusion to tackle bandage slippage on the foot}

\author{
Andreas Nilsson, ${ }^{1}$ Torbjörn Lundh, ${ }^{1,2}$ \\ Josefin Damm \\ ${ }^{1}$ PressCise AB, Herrljunga, Sweden; \\ ${ }^{2}$ Chalmers University of Technology, \\ Gothenburg, Sweden
}

\section{Introduction}

Compression therapy with bandages and stockings is the cornerstone and golden standard in the prevention and treatment of chronic venous leg diseases. ${ }^{1}$ A common problem related to compression treatment with bandages is slippage at and around the foot and heel. Stiff bandages in particular tend to cause slippage due to reduction in limb size during compression treatment, and the inherent inability of the material to recover post-stretch. ${ }^{2}$ Bandage slippage can create local high-pressure areas that may cause tissue damage and even necrosis. ${ }^{3}$ The use of stockings can often reduce this risk of slippage. ${ }^{4,5}$ Moreover, stockings are typically less bulky, help to preserve ankle range of motion, and permit patients to wear normal footwear. However, stockings can be tricky to don, especially when ulcers are involved. An optimal solution for indications that are best treated with bandages on lower extremities seems to be a compression sock on the foot and a bandage on the leg. The transition from sock to bandage, however, must be seamless in order to provide proper compression treatment. Furthermore, the combination needs to be easy to apply, and the transition from sock to bandage must not create local high- or low-pressure zones on the ankle. In order to control pressure at the transition, both the sock and bandage need to have well-defined pressures, which cannot be affected by the applier's experience or the patient's leg size or shape. The need for consistency in contact pressure rules out traditional bandages as they are prone to exert extreme variations in applied pressure. ${ }^{6-9}$

\section{Aim}

To find a compression sock-bandage fusion method that provides well-defined pressure on the foot, around the ankle and along the leg.

\section{Materials and Methods}

Thirteen healthy subjects (six females, seven males) were enrolled.

Three pressure sensors were placed unilaterally on all subjects (A) on the foot, (B) at the ankle and $(\mathrm{C})$ on the calf (Figure 1A).

A short ankle sock (Lundatex ${ }^{\circledR}$ sock, PressCise, Sweden) was applied on the foot, ending just above the malleoli. The sock is designed to provide a pressure of $20 \mathrm{mmHg}$ except for the cuff that is designed to apply only $10 \mathrm{mmHg}$. The same smart textile technology used in the sock has previously been evaluated in a knee-high stocking. ${ }^{10}$ An elastic bandage (Lundatex ${ }^{\circledR}$ medical, PressCise, Sweden) with built-in welldefined and controlled pressure ${ }^{11-13}$ was wrapped along the leg, starting on the cuff of the sock. By this application approximately $5 \mathrm{~cm}$ of bandage covered the cuff (Figure 1B). The bandage is designed to provide $20 \mathrm{mmHg}$ of pressure along the leg, with a $50 \%$ overlap (i.e., each bandage layer provides $10 \mathrm{mmHg}$ of pressure). Hence, the first bandage turn applied a pressure of only $10 \mathrm{mmHg}$ on top of the cuff so that the theoretical total pressure equaled $20 \mathrm{mmHg}$. The bandage was secured to the sock cuff with a MiniLock ${ }^{\mathrm{TM}}$ (PressCise, Sweden), a new type of fastening device in a hookmaterial (Figure 2). The interface pressure from the three sensors was measured with a Picopress ${ }^{\circledR}{ }^{14}$ in supine and standing neutral positions. The pressure sensor was turned on after application of the sock and bandage. This procedure ensured that the applied pressures were blinded to the applier during application of the compression products. Mann-Whitney U-test was used for comparisons, significance set at $\mathrm{P}<0.05$. Correlations are given with Pearson's r.

\section{Results}

The sock-bandage fusion method applied a well-defined pressure at the foot, ankle and leg (Table 1). No significant differences in interface pressures were found between locations $\mathrm{A}, \mathrm{B}$ or $\mathrm{C}$ in supine $(\mathrm{P}>0.7)$ or in standing $(\mathrm{P}>0.11)$ positions.
Correspondence: Andreas Nilsson, PressCise AB, Herrljunga, Sweden.

E-mail: andreas@presscise.com

Conflict of interest: Josefin Damm and Torbjörn Lundh are co-inventors and cofounders of PressCise AB. Andreas Nilsson is the $\mathrm{CEO}$ of PressCise AB.

Conference presentation: International Compression Club (ICC) Meeting, Rotterdam, 2018.

This work is licensed under a Creative Commons Attribution 4.0 License (by-nc 4.0).

(C) Copyright A. Nilsson et al., 2018

Licensee PAGEPress, Italy

Veins and Lymphatics 2018; 7:7977

doi:10.4081/vl.2018.7977

Foot, ankle and leg circumference ranges were $20.5-29 \mathrm{~cm}, 19.7-29 \mathrm{~cm}$ and $23.2-35 \mathrm{~cm}$, respectively.

Low correlation was found between interface pressures from the compression solution and circumference in both supine $(\mathrm{r}=0.17)$ (Figure $3 \mathrm{~A})$ and standing positions $(r=0.29)$ (Figure 3B).

\section{Discussion}

The presented fusion method of using a short compression sock together with a bandage applied a well-defined pressure without creating high- or low-pressure areas where the compression sock ended and the bandage began. The sock applied $20 \mathrm{mmHg}$ in mean pressure although the sensor placement on the foot occurred in a rather flat location (low curvature). This result is likely due to the pressure-control textile technology used in the sock.

Applied pressures on the leg from the bandage were very consistent with a minimal standard deviation despite the differences in leg sizes among the patients. Furthermore, there was no correlation between leg size and pressure (Figure 3), which demonstrates that the bandage applied correct pressure regardless of leg

Table 1. Interface pressures ( $\mathrm{mmHg}$ ) with standard deviation measured simultaneously with three sensors in supine and standing positions.

\begin{tabular}{lcccccc} 
& \multicolumn{2}{c}{ Foot (A) } & \multicolumn{2}{c}{ Ankle (B) } & \multicolumn{2}{c}{ Leg (C) } \\
& Mean & SD & Mean & SD & Mean & SD \\
Supine & 20 & 2.9 & 20 & 2.4 & 21 & 1.6 \\
Standing & 20 & 3.9 & 21 & 3.2 & 22 & 2.0 \\
\hline
\end{tabular}




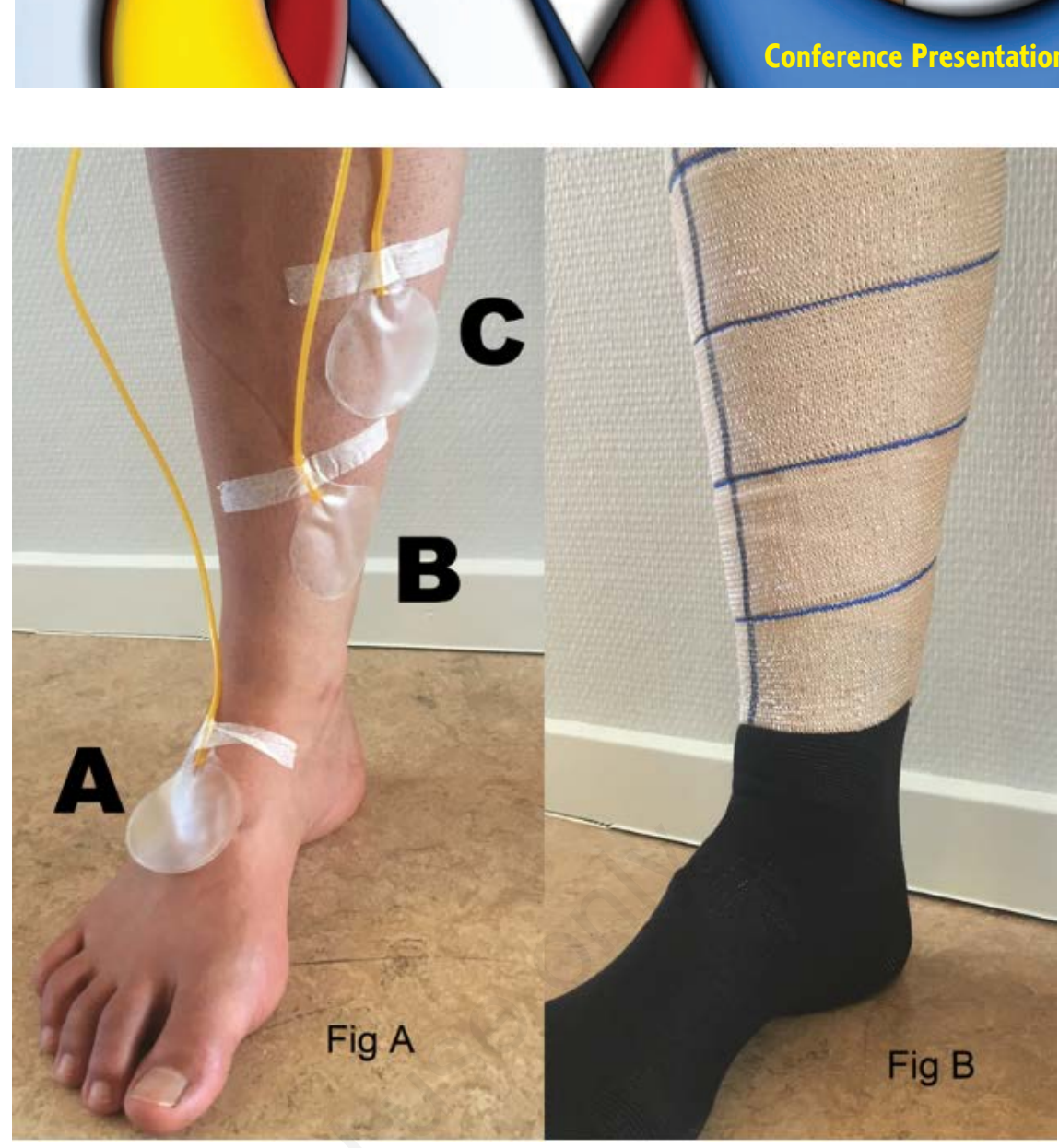

size and shape. This feature is unique to the bandage and may improve the safety and effectiveness of the compression treatment it offers. The results were achieved despite the fact that the applier was not using the pressure sensor readings for feedback. Interface pressures are rarely stated in papers on bandage compression treatment. ${ }^{15}$ The consistent pressures presented in the current study are in contrast to reports on application of traditional bandages that usually exert extremely variable pressures. . $^{6}$ 9,16,17 The results in the present study confirm previous studies on this special bandage. ${ }^{11-13}$

Interface pressures on the foot and ankle areas were fairly consistent between subjects despite the same sock sample was used on all subjects. This indicates that correct compression is ensured without a need for custom-fitting of the sock.

The fusion method was easy to apply partly due to the patented MiniLock ${ }^{\mathrm{TM}}$. The lock secures the initial turn of the bandage without the need for a locking bandage turn first. This may be an important feature to make self-management easier.

sion treatment is influenced by factors such as pain, discomfort and bulkiness of the compression garment. ${ }^{18-20}$ Furthermore, bulky compression garments over the ankle area may obstruct a normal range of motion, inhibiting the natural venous pumping function of the foot/ankle, hindering the usage of normal footwear, and thereby possibly reducing the patients' ability to keep up with daily exercise. Maintaining daily exercise and a normal gait is key to preserving tissue viability. The proposed fusion solution may not only prevent bandage slippage on the foot, but it may help patients preserve their full ankle range of motion and allow them to wear normal footwear.

\section{Limitations}

This fusion method will not be possible with traditional bandages; it requires a bandage with built-in pressure control ${ }^{11-13}$ and a sock with assured pressure regardless of foot/ankle size.

\section{Other possible applications of the smart textile sock}

The sock could potentially be used separately when a well-defined compression is needed. Layering a sock on top of a bandage-wrapped foot could be an option when higher compression on the foot is desired.

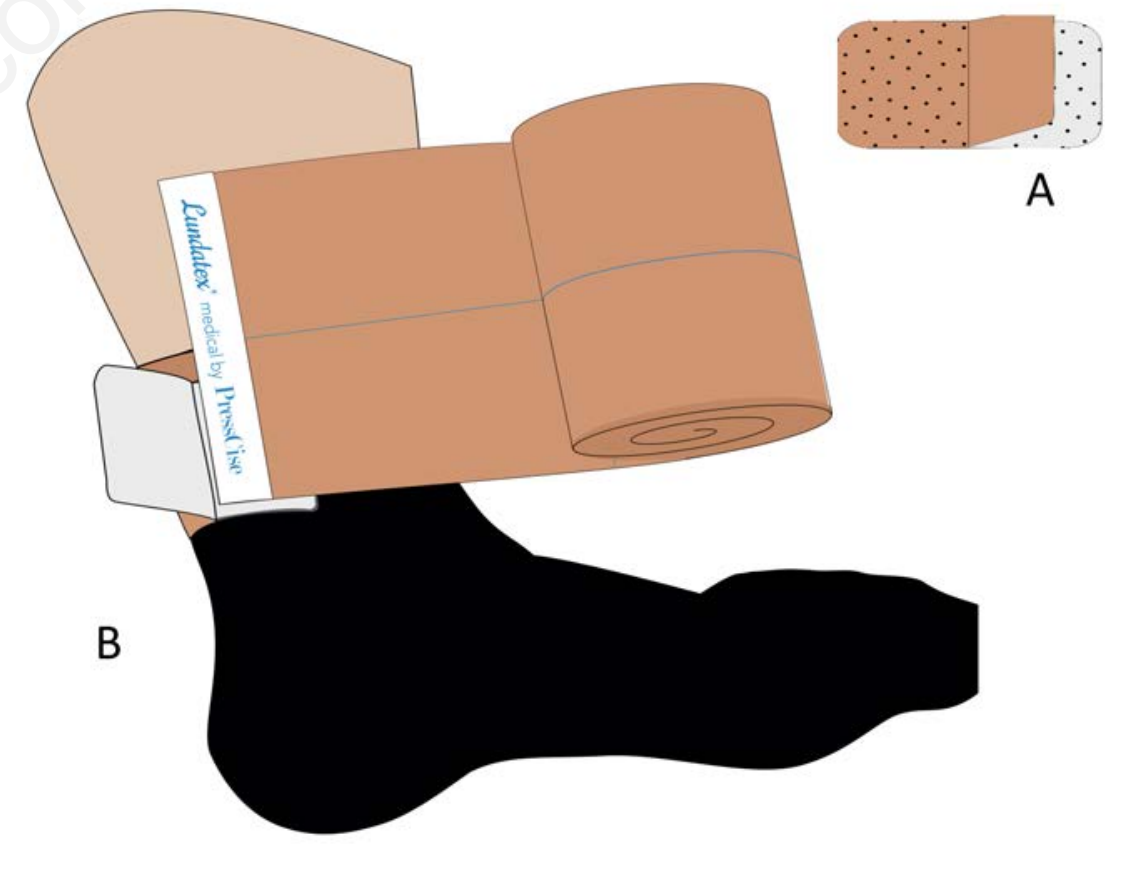

Figure 2. A) The MiniLock, a special fastening device, and B) The transition between sock and bandage using the MiniLock. 

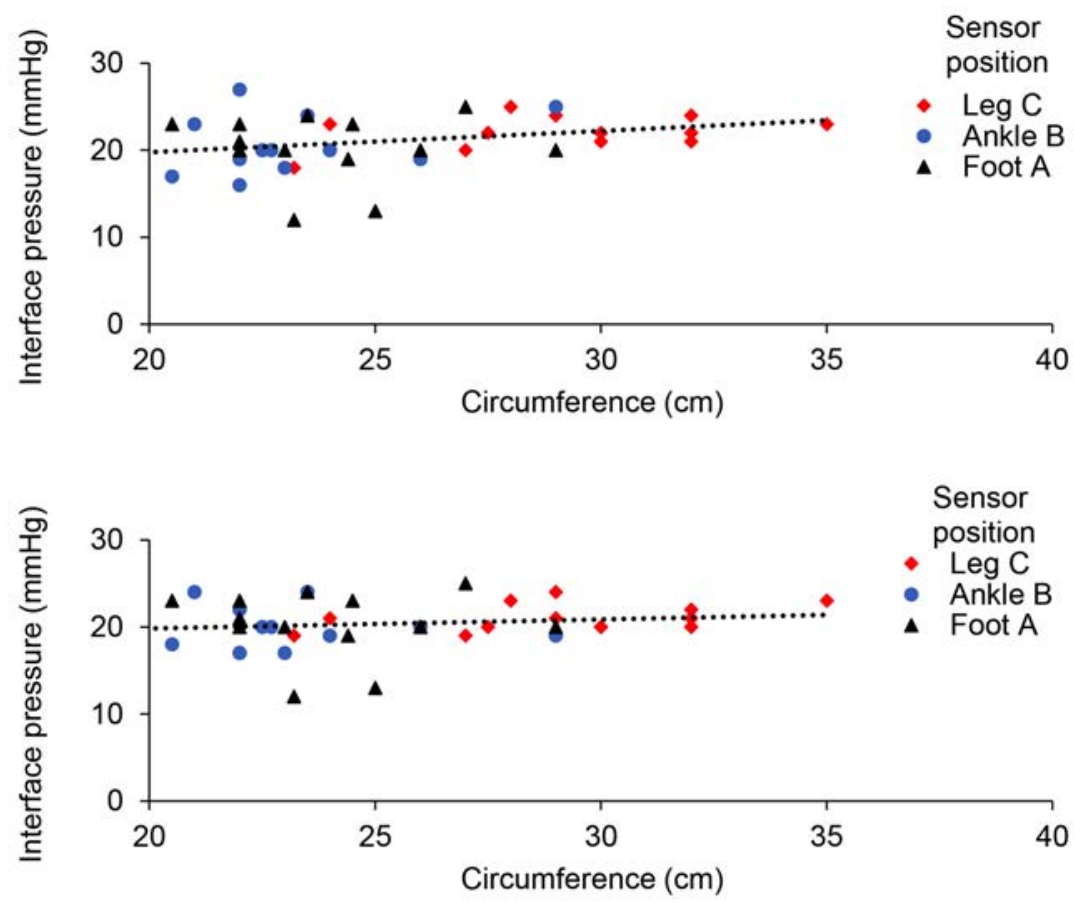

Figure 3. Interface pressures measured simultaneously with three sensors at location A, $B$, and $C$ showed low correlation to circumference both in supine position (3A) and in standing position (3B).

\section{Conclusions}

This solution provides a safe, well-controlled pressure on the foot, around the ankle and along the leg. The sock eliminates bandage slippage on the foot and makes self-management easier. It may also help patients preserve their full ankle range of motion and allow them to wear normal footwear.

\section{References}

1. Partsch H. Understanding the pathophysiology of compression. In: Understanding compression therapy: EWMA Position Document; 2003.

2. Moffatt C. Variability of pressure provided by sustained compression. Int Wound J 2008;5:259-65.
3. Thomas S. Compression bandaging in the treatment of venous leg ulcers. World Wide Wounds 1998;1-15.

4. Amsler F, Willenberg T, Blättler W. In search of optimal compression therapy for venous leg ulcers: A meta-analysis of studies comparing diverse bandages with specifically designed stockings. J Vasc Surg 2009;50:668-74.

5. Nørregaard S, Bermark S, Gottrup F. Do ready-made compression stockings fit the anatomy of the venous leg ulcer patient? J Wound Care 2014;23:128-35.

6 . Protz K. Compression therapy: scientific background and practical applications. J Dtsch Dermatol Ges 2014;12:794-801.

7. Nelson EA, Ruckley CV, Barbenel JC. Improvements in bandaging technique following training. J Wound Care 1995;4:181-4.

8. Keller A, Müller ML, Calow T, et al. Bandage pressure measurement and training: Simple interventions to improve efficacy in compression bandaging. Int Wound $\mathrm{J}$ 2009;6:324-30.

9. Zarchi K, Jemec GBE. Delivery of compression therapy for venous leg ulcers. JAMA Dermatol 2014;150:7306.

10. Nilsson A, Lundh T. A new stocking compression system with a low welldefined resting pressure and a high working pressure. Veins Lymphatics 2018;7.

11. Wiklander K, Andersson AE, Källman $\mathrm{U}$. An investigation of the ability to produce a defined 'target pressure' using the PressCise compression bandage. Int Wound J 2016;13:1336-43.

12. Damm J, Lundh T, Partsch H, Mosti G. An innovative compression system providing low, sustained resting pressure and high, efficient working pressure. Veins Lymphatics 2017;6.

13. Mosti G, Partsch H. A new two component compression system turning an elastic bandage into an inelastic compression device: interface pressure, stiffness, and haemodynamic effectiveness. Eur J Vasc Endovasc Surg 2018;55:126-31.

14. Partsch H, Mosti G. Comparison of three portable instruments to measure compression pressure. Int Angiol 2010;29:426-30.

15. Mosti G. Elastic stockings versus inelastic bandages for ulcer healing: a fair comparison? Phlebology 2012;27:1-4.

16. Reynolds, S. The impact of a bandage training programme. J Wound Care 1999;8:55-60.

17. Nelson EA. Compression bandaging in the treatment of venous leg ulcers. J Wound Care 1996;5:415-8.

18. Bale S, Harding KG. Managing patients unable to tolerate therapeutic compression. Br J Nurs 2003;12:S4-13.

19. O’Meara S, Cullum N, Nelson EA, Dumville JC. Compression for venous leg ulcers. Cochrane Database Syst Rev 2012;11:CD000265.

20. Weller CD, Buchbinder R, Johnston RV. Interventions for helping people adhere to compression treatments for venous leg ulceration. Cochrane Database Syst Rev 2013 [Epub ahead of print]. 